\title{
Pacemaker implantation in patients with major depression, should it be of concern? A case report and literature review
}

\author{
Xiaoru Che ${ }^{1,2}$, Youssef S. Abdelwahed ${ }^{2,3,4}$, Xiaoyu Wang ${ }^{5}$, Yuanjian Fang ${ }^{5}$ and Lihong Wang ${ }^{*}$ (D)
}

\begin{abstract}
Background: Psychological adaptation after cardiac pacemaker implantation is a challenge for patients with mental illness.

Case presentation: Here we report a self-harming patient with a psychiatric disorder. A 73-year-old female patient with 16-year coronary heart disease and a 4-year depression was admitted to our hospital for a coma. Two months earlier, the local hospital confirmed that the patient had a second-degree sinoatrial (SA) block (type 2) as well as basal septal hypertrophy with the left ventricular outflow obstruction. Therefore, metoprolol sustained-release tablets $95 \mathrm{mg}$ QD and diltiazem sustained-release tablets $90 \mathrm{mg}$ QD was given as treatment after a pacemaker was implanted. However, the patient had continued complaining about discomfort due to the pacemaker implanted after being discharged from the hospital. Two months later, she attempted to commit suicide by removing her pacemaker and taking 80 sleeping pills. After a series of treatments, the patient improved and was discharged without a pacemaker re-implantation. With continued anti-depression treatment and strengthen family supervision, the patient's condition is stable now.
\end{abstract}

Conclusions: A suicide attempt by intentionally removing the permanent pacemaker system was rarely reported. In bradycardia patients with a history of psychological or psychiatric disease, careful evaluation should be done before and after implantation of the pacemaker.

Keywords: Pacemaker implantation, Depression, Psychological disease, Psychiatric disease, Suicide

\section{Background}

Psychological adaption after pacemaker implantation can be challenging in patients with confirmed or undetected psychiatric disorders. We represent a case of attempted suicide by the intended self-removal of a permanent pacemaker system before ingestion of 80 tablets of alprazolam in a patient with a history of major depression for four years. This case was an extreme adverse event of a depressed patient with a pacemaker. Until now, only

\footnotetext{
* Correspondence: sananc@163.com

'Department of Cardiology, Zhejiang Provincial People's Hospital, People's Hospital of Hangzhou Medical College, NO.158 Shangtang Rd, 310014 Hangzhou, People's Republic of China

Full list of author information is available at the end of the article
}

6 cases of severe self-harm behavior after pacemaker implantation in patients with mental diseases were reported. This case report and literature review may promote a better understanding of how to deal with a pacemaker patient with mental disease and have significant implications in clinical practice.

\section{Case presentation}

A 73-year-old woman was admitted to the hospital due to a coma. Upon arrival in the emergency room (ER), the patient was found unconscious and then she was intubated due to her Glasgow Coma Scale (GCS) was 6 as well as her low blood oxygen saturation. Her other vital signs were stable. Electrocardiogram (ECG) showed

(c) The Author(s). 2020 Open Access This article is licensed under a Creative Commons Attribution 4.0 International License, which permits use, sharing, adaptation, distribution and reproduction in any medium or format, as long as you give appropriate credit to the original author(s) and the source, provide a link to the Creative Commons licence, and indicate if changes were made. The images or other third party material in this article are included in the article's Creative Commons licence, unless indicated otherwise in a credit line to the material. If material is not included in the article's Creative Commons licence and your intended use is not permitted by statutory regulation or exceeds the permitted use, you will need to obtain permission directly from the copyright holder. To view a copy of this licence, visit http://creativecommons.org/licenses/by/4.0/. The Creative Commons Public Domain Dedication waiver (http://creativecommons.org/publicdomain/zero/1.0/) applies to the data made available in this article, unless otherwise stated in a credit line to the data. 
sinus rhythm with heart rate at $70 \mathrm{bpm}$, and the blood pressure (BP) was around $130 / 70 \mathrm{mmHg}$. There was a self-inflicted wound on her left upper chest, and two silicone-caps were found in the injury. According to the patient family members, two hours before, they suddenly discovered the patient unconscious on the bedroom floor with severe trauma on her left upper chest (Fig. 1). They also found an empty packet of sleeping pills on the room floor next to the patient. Furthermore, the family detected the pacemaker and electrode lines outside the window (Fig. 2). Therefore, they assumed that the patient had removed the pacemaker and taken drugs to commit suicide. The patient's medical history indicated that she had a history of coronary heart disease for 16 years and depression for 4 years. She had implanted two stents separately and has a long-term used aspirin, atorvastatin, and metoprolol sustained-release tablets to treat heart disease. She usually took alprazolam and paroxetine for relieving depression.

Two months earlier, the patient was admitted to another hospital due to syncope. The echocardiography was performed at that hospital showed basal septal hypertrophy and a narrow left ventricular outflow tract. Moreover, the patient underwent coronary angiography, which could exclude significant coronary artery stenosis. Intermittent left ventricular outflow tract obstruction was proven by cardiac catheterization and invasive pressure measurements. The dynamic electrocardiogram (DCG) report pointed out that the patient has a seconddegree sinoatrial (SA) block (type 2). Since the patient and her family members decided not to perform septal ablation, so the patient underwent a dual-chamber pacemaker implantation due to her intermittent bradycardia during that hospitalization. The pacing generator was placed subcutaneously in the left infraclavicular region, and the two-chamber pacing leads were fixed in the

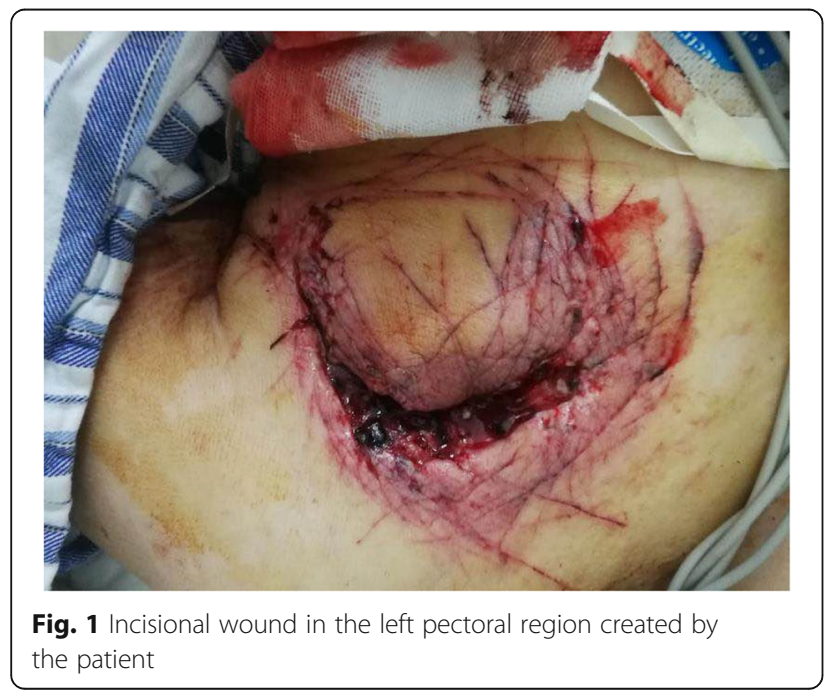

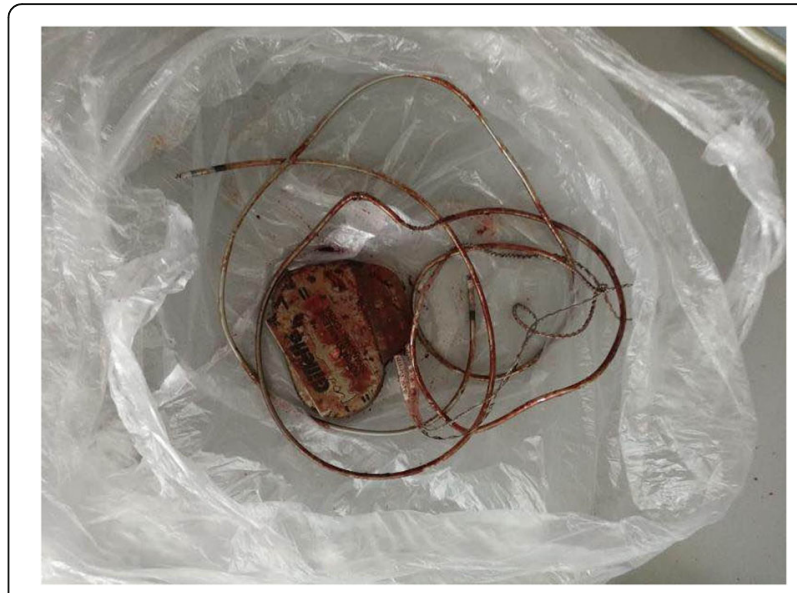

Fig. 2 Pacemaker and electrode line extracted by the patient

right auricle and the right ventricular apex respectively through the left subclavian vein (BIOTRONIK Evia DR$\mathrm{T}$ 68955978). Post-operative administration includes metoprolol sustained-release tablets $95 \mathrm{mg}$ QD and diltiazem sustained-release tablets $90 \mathrm{mg}$ QD treatment. Her family members mentioned that the patient had kept complaining about discomfort after she was discharged from the hospital, and she suspected her condition "had been aggravated" by the pacemaker. However, the family members did not pay any attention.

In the ER, the chest radiograph indicated that the pulse generator and the pacing leads had been removed entirely (Fig. 3). There were no signs of cardiac perforation, vascular injury, or pericardial effusion by ultrasonography (Fig. 4). We performed the anti-infective

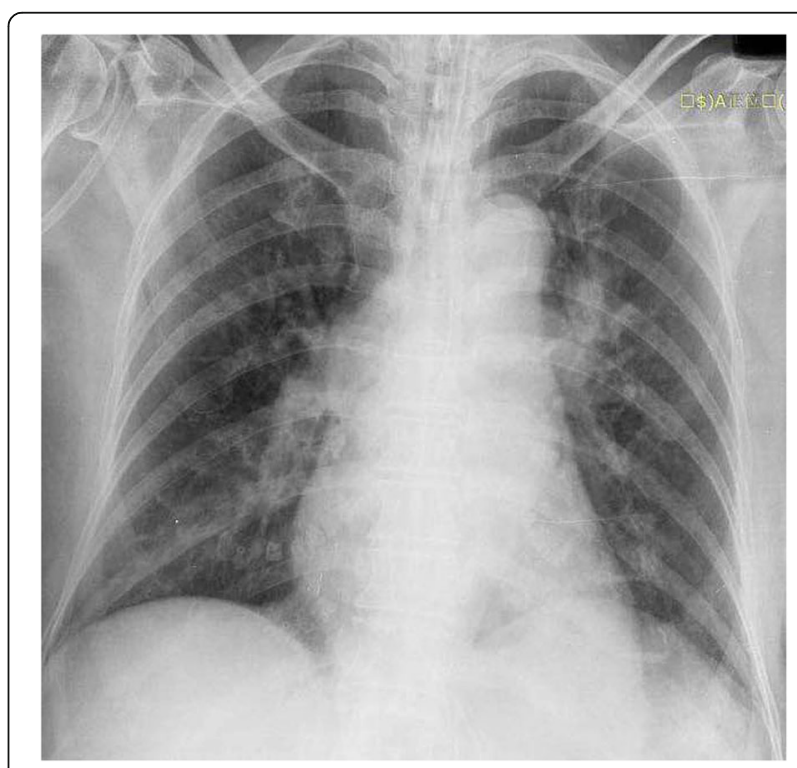

Fig. 3 Chest x-ray demonstrating the pulse generator and the pacing leads have been removed completely 


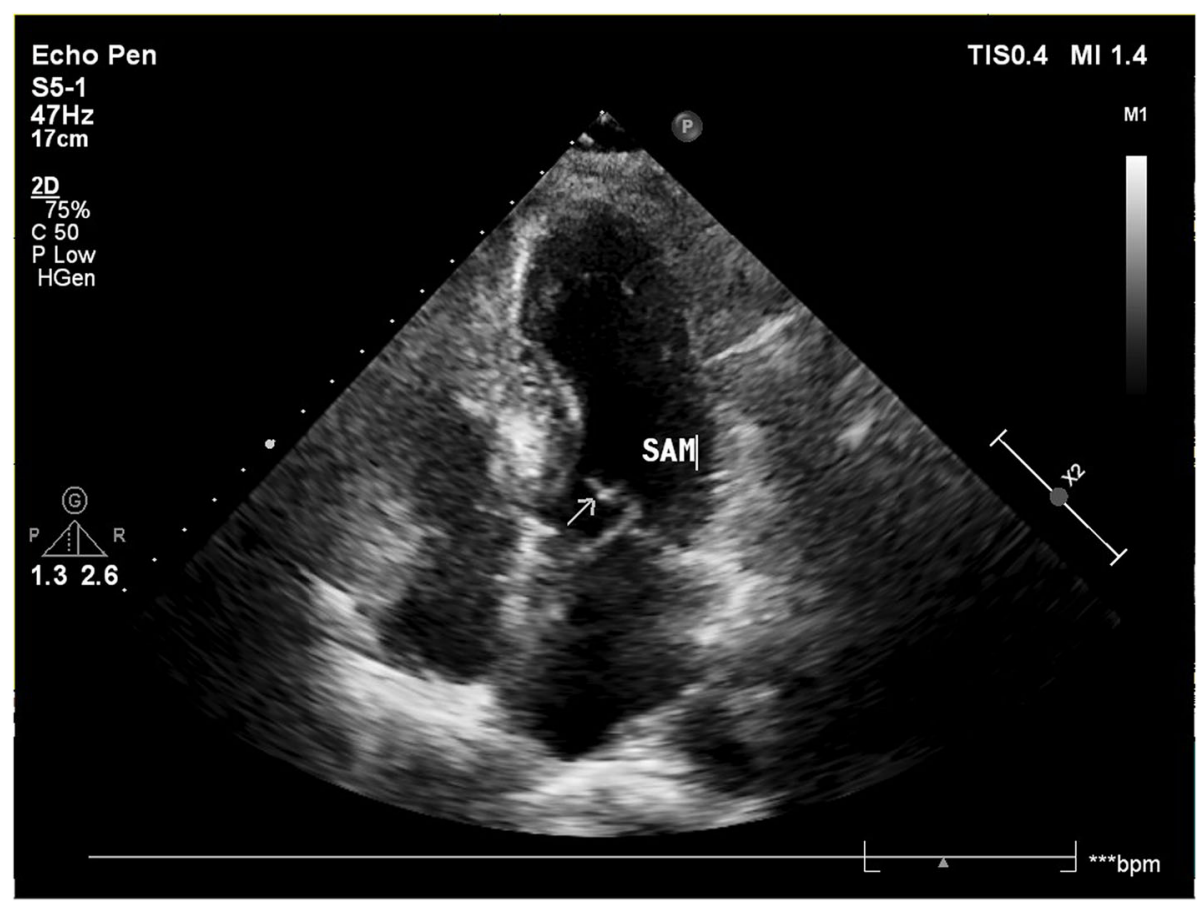

Fig. 4 Septal hypertrophy with SAM showed in ultrasonography and no sign of pericardial effusion

treatment on the patient and surgical debridement after removed the pacemaker system residues. The electrocardiographic monitoring did not record the events of bradycardia, so a temporary pacemaker was not implanted. The patient awoke one day after. She admitted that she has gone to see the psychiatrist regularly in the hospital but has not taken any antidepressant medication prescribed by the doctor since she was last discharged from the hospital. On the day of admission to our hospital, she cut the pacemaker pocket with a knife, extracted the pacemaker by hand, and then she attempted to kill herself with 80 alprazolam tablets. As the patient and her family members refused to continue treatment in the cardiology department, they immediately left the hospital upon the improvement of the patient's condition. Considering the particularity of this patient's condition, the patient discharged from our hospital with aspirin, atorvastatin, and metoprolol sustainedrelease tablets $23.75 \mathrm{mg}$ QD for her cardiac disease. To this time, no severe arrhythmias are detected during the patient's regular visits, and no syncope symptoms occurred. With continued antidepressant treatment and strengthen family supervision, the patient's condition is stable.

\section{Discussion and conclusions}

Self-harm and suicidal tendencies are common in patients with mental diseases, such as depression. Selfharm is often impulsive. A terrible state of mind would be a trigger of self-harm intention [1]. This case was an extreme adverse event of a depressed patient with a pacemaker. As far as we know, severe self-harm behavior by destroying pacemaker and attempting suicide as this case had only been reported in 6 case reports (Table 1) [2-7]. In these reports, suicidal behaviors occur between 2 weeks and 12 years after pacemaker implantation, including the use of knife, gun, razor blade, and hand to destroy the pacemaker and attempt to commit suicide $[2,3,5,7]$. One patient died of sepsis after six days, and others recovered after treatment [6].. In our case, the patient was lucky because the pacemaker was implanted recently. Thus, the pulse generator and the leads may be removed easily since the implants didn't adhere tightly to the surrounding tissues. However, the risks of selfremoval of pacemakers can be severe and fatal over time. To the best of our knowledge, the risks may include infection, chest wall injury, vascular injury, major bleeding, and even cardiac rupture. In those previous cases, the causes of suicide are all related to depression. Three patients have depression history before the pacemaker was implanted. The other three patients, although there was no established depression, the mental problems induced by their physical condition or family issues were detected and started with anti-depression therapy during their hospitalization. We also present a case with a depression history, attempted suicide after pacemaker implantation. In this case, the patient has a history of depression for four years, but her depression condition 
Table 1 The main literature of suicide after pacemaker implantation in patients with psychotic diseases

\begin{tabular}{|c|c|c|c|c|c|c|c|c|}
\hline Literature & Author & Years & Ages & Gender & $\begin{array}{l}\text { Pacemaker } \\
\text { time }\end{array}$ & $\begin{array}{l}\text { Pacemaker re- } \\
\text { implantation }\end{array}$ & $\begin{array}{l}\text { Psychotic history before } \\
\text { pacemaker }\end{array}$ & Outcome \\
\hline Case 1 & Rosenthal et al .[2] & 1980 & $81 y$ & Male & $6 m$ & Yes & No & $\overline{\text { Recovered }}$ \\
\hline Case 2 & Simon et al .[3] & 1980 & $53 y$ & Female & $10 y$ & * & Yes & Recovered \\
\hline Case 3 & Harthorne J W[4] & 1980 & $79 y$ & Male & $11 y$ & Yes & No & Recovered \\
\hline Case 4 & $\begin{array}{l}\text { Hochmeister et al } \\
\text { [5] }\end{array}$ & 1989 & $59 y$ & Male & Not mentioned & Yes & Yes & Recovered \\
\hline Case 5 & Bordier et al .[6] & 2004 & $70 y$ & Male & $14 d$ & No & Not established & Died \\
\hline Case 6 & Norgaard et al. [7] & 2014 & $70 y$ & Male & $12 y$ & Yes & Yes & Recovered \\
\hline
\end{tabular}

*The previous pacemaker's normal function was still present, not change

was not under control since she withdrew the antidepression medication. While we talked with her family, we further knew that her husband slept in a separate room, and he never knew with his wife's medication. Even, the patient had kept complaining about the pacemaker made her even worse, which meant that she could not adapt or accept the device, her family still paid no attention.

Psychological adaption after pacemaker implantation can be challenging in patients with confirmed or undetected psychiatric disorders [8]. From the reported literature, the early discussion focused on improving the volume and function of the pacemaker to reduce the hostility or discomfort to the patients. Nowadays, with the pacemaker optimization, the focus is more on the particular group of people with depression itself. We present another unique case that raises the issue of whether adequate evaluation and feasible criterion for pacemaker implantation should be considered in certain groups of patients? In a study by Arthur B. Simon et al., a randomized 30 patients with a cardiac pacemaker in their outpatient follow-up survey found that $20 \%$ of patients had a veiled depression or even a wish to die [3]. Młynarski R reported, 98 patients with atrioventricular blocks (AVB) showed a higher level of anxiety or depression after pacemaker implantation than preoperative by questionnaire [9]. Likewise, high levels of anxiety and depression were observed in 27.2 and $14.0 \%$, respectively, in the 250 patients with a permanent cardiac pacemaker in Maria Polikandrioti et al.'s study [10]. All these studies showed that psychological problems such as depression have a considerable proportion of patients with pacemakers. The implanted life-saving device may involve a severe psychological burden to recipients or aggravate their symptoms. Physicians who usually pay more attention to the technical aspects of the device need to enhance awareness about psychological distress among those patients. Among patients with a pacemaker, especially in cases with a history of mental illness or suspected instances, routine follow-up, along with the systematic evaluation of anxiety or depression, and consultation with psychiatrists are necessary. Family education of depression patients is also essential.

Implantable cardioverter-defibrillator (ICD) therapy is not indicated in patients with significant psychiatric illnesses that may be aggravated by device implantation, or that may preclude systematic follow-up (Level of Evidence: C) $[11,12]$. There is no question that depression should not be an absolute contraindication to permanent cardiac pacing, since chronic bradycardia may be the cause of depression and cognitive impairment, in which cases will have distinctly beneficial effects from pacemaker implantation [13]. Udo et al. have described the significant improvement of the health-related quality of life (HRQoL) in a large scale of pacemaker patients. Reason not to deny pacing to patients with mental disorders or psychiatric diseases [14]. However, a multidisciplinary assessment for patients with mental disorders or psychiatric diseases is of great importance due to pacemaker implantation's potential risks of deteriorating patients' psychological conditions. It is advisable to make clear the indication to avoid unnecessary implantations. More and better post-implant surveillance in a multidisciplinary setting should be advocated.

In conclusion, suicide attempts by intentionally removing the permanent pacemaker system are rare but have severe and adverse outcomes. The indication of pacemaker implantation should always be guided by evidence. Besides, patients and their relatives must be engaged in the decision-making process. But for these patients with mental illness, psychological or psychiatric support should be provided, a multidisciplinary assessment before and after implanting becomes essential for those patients. Even so, it is still hard to foresee the risk of self-harm or suicide in these patients; thus, the need for a feasible criterion is highlighted.

\section{Abbreviations}

ER: Emergency room; BP: Blood pressure; SA: Second-degree sinoatrial; ECG: Electrocardiogram; GCS: Glasgow coma scale; DCG: Dynamic electrocardiogram

Acknowledgements

None. 


\section{Consent to publication}

Written informed consent was obtained from the patient's son for publication of the patient's personal and clinical details along with identifying images. Because the patient was assessed by a professional psychiatrist according to Mini-mental State Examination and Hamilton Depression Scale. And the patient was deemed to be incapable of providing consent for his personal and clinical details which was evaluated by the psychiatrist.

\section{Authors' contributions}

Concept/design: X. C and L.W; Drafting article: X.W; Critical revision of article: Y. F and YA; Approval of article: L.W; Funding secured by X. C and L.W. All authors have read and approved the manuscript.

\section{Funding}

X.C was funded by Zhejiang Provincial Health Department Project (2018260820) and Zhejiang Province Department of Education Project (Y201738256). The funding body had no role in in the design of the study, collection of data and writing of the study.

\section{Availability of data and materials}

The datasets used in the case are available from the corresponding author upon reasonable request.

\section{Ethics approval and consent to participate}

The Institutional Review Board of Zhejiang Provincial People's Hospital approved this study.

\section{Competing interests}

The authors report no conflict of interest.

\section{Author details}

'Department of Cardiology, Zhejiang Provincial People's Hospital, People's Hospital of Hangzhou Medical College, NO.158 Shangtang Rd, 310014 Hangzhou, People's Republic of China. ${ }^{2}$ Department of Cardiology,

Charite'-University Medicine Berlin, Campus Benjamin Franklin, Hindenburgdamm 30, 12203 Berlin, Germany. ${ }^{3}$ DZHK (German Centre for Cardiovascular Research), partner site Berlin, Oudenarder Str. 16, 13347 Berlin, Germany. ${ }^{4}$ Berlin Institute of Health (BIH), Berlin, Anna-Louisa-Karsch-Straße 2, 10178 Berlin, Germany. ${ }^{5}$ Department of Neurosurgery, The second affiliated Hospital, Scholl of Medicine, Zhejiang University, Hangzhou, China.

Received: 12 December 2019 Accepted: 2 June 2020

Published online: 09 June 2020

\section{References}

1. Skegg K. Self-harm. Lancet (London, England). 2005;366:1471-83.

2. Rosenthal R, Crisafi BR, Coomaraswamy RP. Manual extraction of a permanent pacemaker: an attempted suicide. Pacing Clin Electrophysiol. 1980:3:229-31.

3. Simon $A B$, Kleinman $P$, Janz N. Suicide attempt by pacemaker system abuse: a case report with comments on the psychological adaptation of pacemaker patients. Pacing Clin Electrophysiol. 1980;3:224-8.

4. Harthorne JW. Attempted suicide by self-removal of implanted pacemaker. Pacing Clin Electrophysiol. 1980;3:740-1.

5. Hochmeister MN, Seifert D, Smetana R, Czernin J. Suicide attempted by aiming slaughtering gun at pacemaker. Am J Forensic Med Pathol. 1989;10:268.

6. Bordier P, Robert F. Suicide by self-removal of a pacemaker. Am J Forensic Med Pathol. 2004:25:78-9.

7. Norgaard ML, Melchior T, Wagner T, Haugan K. Suicide attempt by complete self-removal of a 12-year-old permanent pacemaker system: case report. J Cardiovasc Electrophysiol. 2014;25:99-100.

8. Lampert R. Managing with pacemakers and implantable cardioverter defibrillators. Circulation. 2013:128:1576-85.

9. Młynarski R, Włodyka A, Kargul W. Changes in the mental and physical components of the quality of life for patients six months after pacemaker implantation. Cardiol J. 2009;16:250-3.

10. Polikandrioti M, Tzirogiannis K, Zyga S, Gerogianni G, Stefanidou S, Tsami A, et al. Assessment of fatigue in patients with a permanent cardiac pacemaker: prevalence and associated factors. Arch Med Sci Atheroscler Dis. 2018;3:e166-73.
11. Brignole $M$, Auricchio A, Baron-Esquivias $G$, Bordachar P, Boriani $G$, Breithardt OA, et al. 2013 ESC guidelines on cardiac pacing and cardiac resynchronization therapy: the task force on cardiac pacing and resynchronization therapy of the European Society of Cardiology (ESC). Developed in collaboration with the European heart rhythm association (EHRA). Eur Heart J. 2013;34:2281-329.

12. Epstein AE, DiMarco JP, Ellenbogen KA, Estes NA 3rd, Freedman RA, Gettes LS, et al. 2012 ACCF/AHA/HRS focused update incorporated into the ACCF/ AHA/HRS 2008 guidelines for device-based therapy of cardiac rhythm abnormalities: a report of the American College of Cardiology Foundation/ American Heart Association task force on practice guidelines and the Heart Rhythm Society. J Am Coll Cardiol. 2013;61(3):e6-75.

13. Rampertaap MP. Depression in a geriatric patient: alleviation by insertion of a pacemaker. South Med J. 1986;79:1043-4.

14. Udo EO, van Hemel NM, Zuithoff NP, Nijboer H, Taks W, Doevendans PA, et al. Long term quality-of-life in patients with bradycardia pacemaker implantation. Int J Cardiol. 2013;168:2159-63.

\section{Publisher's Note}

Springer Nature remains neutral with regard to jurisdictional claims in published maps and institutional affiliations.

\section{Ready to submit your research? Choose BMC and benefit from:}

- fast, convenient online submission

- thorough peer review by experienced researchers in your field

- rapid publication on acceptance

- support for research data, including large and complex data types

- gold Open Access which fosters wider collaboration and increased citations

- maximum visibility for your research: over $100 \mathrm{M}$ website views per year

At BMC, research is always in progress.

Learn more biomedcentral.com/submissions 